\title{
Splitting error estimation for micro-physical-multiphase chemical systems in meso-scale air quality models
}

\author{
Frank Müller* \\ Max Planck Institute for Meteorology, Bundesstrasse, 55, 20146 Hamburg, Germany
}

Received 20 December 2000; received in revised form 20 June 2001; accepted 6 July 2001

\begin{abstract}
Operator splitting applied to cloud micro-physical and multiphase chemical process causes the so-called operator splitting errors in addition to other numerical errors when used in numerical models. Operator splitting is mainly used due to limited computer resources or for historical reasons. Unfortunately, it is impossible so far to theoretically estimate either the order of magnitude or the tendency of the splitting errors in complex non-linear systems such as mutually interacting cloud chemical and micro-physical processes.

The present study systematically investigates the splitting error mentioned above, by numerical means to define valid ranges of the applicability of the method of operator splitting to those systems. Results of the current study show that de-coupling intervals larger than $100 \mathrm{~s}$ cause an underestimation of the total liquid water content as well as the particle radius of the order of $10 \%$ for simulation periods of $1000 \mathrm{~s}$. The maximum overprediction of the total content of dissolved material in the particles is of the order of about $20 \%$ for de-coupling intervals of $10-15 \mathrm{~min}$. The error in the sulphate production contributes about $50 \%$ to the discrepancy in total aerosol content. Since the de-coupling intervals between dynamical, micro-physical, and chemical processes in most recent air quality models are considerably longer than $15 \mathrm{~min}$, the consequences of the application of operator splitting requires further investigation with respect to predicted aerosol formation, cloud water content, deposition rates, photo-chemistry, cloud optical properties, etc. (C) 2001 Elsevier Science Ltd. All rights reserved.
\end{abstract}

Keywords: Operator splitting; Air quality; Numerical modelling; Micro-physics; Multiphase chemistry

\section{Introduction}

Simultaneous numerical simulation of the change of pollutant concentrations due to dynamical, microphysical, and multiphase chemical processes in multidimensional models based on the well known advectiondiffusion-reaction equation

$$
\begin{aligned}
& \frac{\partial c}{\partial t}=-\nabla \cdot(\vec{v} c)-\frac{\partial}{\partial r_{\mathrm{s}}}\left(\dot{r}_{\mathrm{s}} c\right)+\nabla \cdot(K \nabla c)+R(c)=L_{\mathrm{ch}}(\vec{x}, c) \\
& c=c(\vec{x}, t), \quad \vec{x} \in \mathfrak{R}^{4}
\end{aligned}
$$

\footnotetext{
*Corresponding author. Tel.: +49-40-4123-5590; fax: +4940-4117-3350.

E-mail address: frank.mueller@dkrz.de (F. Müller).
}

is very demanding on computer resources. Therefore, the application of such numerical models even with modern computer resources often requires a functional separation of the overall model and a separate sequential solution of the corresponding sub-problems. According to Eq. (1a) this can be expressed as

$$
\begin{aligned}
\frac{\partial c}{\partial t} & =L_{\mathrm{ch}, 1}(\vec{x}, t)+L_{\mathrm{ch}, 2}(\vec{x}, t)+L_{\mathrm{ch}, 3}(\vec{x}, t)+L_{\mathrm{ch}, 4}(\vec{x}, t) \\
& =L_{\mathrm{ch}}(\vec{x}, t),
\end{aligned}
$$

$t \in\left[t_{0}, T\right], \quad \vec{x} \in \mathfrak{R}^{4}, \quad c\left(\vec{x}, t_{0}\right)=c_{0}(\vec{x})$.

In Eqs. (1a) and (2a) $c$ is vector-valued in $\mathfrak{R}^{m}$ representing species concentration in any phase, while $L_{\mathrm{ch}}$ and $L_{\mathrm{ch}, i}$ stand for non-linear vector functions or spatial derivative operators in $\mathfrak{R}^{m}$, and $\vec{x}=\left(x, y, z, r_{\mathrm{s}}\right)$ 
and $\vec{v}=(u \vec{i}, v \vec{j}, w \vec{k})$ are the generalized spatial vectors and the corresponding velocities. $r_{\mathrm{s}}$ is the size coordinate of the particle population, and $\dot{r}_{\mathrm{s}}$ is the corresponding velocity which is related to the growth rate of the particles due to condensation/evaporation of volatile compounds. The terms of the r.h.s of Eqs. (1a) and (2a) describe the spatial transport of $c$ (first term), the transport of $c$ along the particle size coordinate due to phase changes (condensation/evaporation) (second term), turbulent transport (third term), and production/destruction rates of $c$ such as chemical reactions, emissions, deposition, as well as changes of $c$ due to micro-physical processes (e.g. particle scavenging, coagulation, etc.) (fourth term).

The averaged budget equation of related changes of the water mass concentration, $G_{\mathrm{w}}$, (likewise, the number concentration could be used) of the suspended particles, which establish the environment for aqueous phase chemical reactions, can be written as

$$
\begin{aligned}
\frac{\partial G_{\mathrm{w}}}{\partial t} & =-\nabla \cdot\left(\vec{v} G_{\mathrm{w}}\right)-\frac{\partial}{\partial r_{\mathrm{s}}}\left(\dot{r}_{\mathrm{s}} G_{\mathrm{w}}\right)+\nabla \cdot\left(K \nabla G_{\mathrm{w}}\right)+R\left(G_{\mathrm{w}}\right) \\
& =L_{\mathrm{mp}}\left(\vec{x}, G_{\mathrm{w}}\right)
\end{aligned}
$$$$
G_{\mathrm{W}}=G_{\mathrm{w}}(\vec{x}, t), \quad \vec{x} \in \mathfrak{R}^{4} .
$$

The first three terms of the r.h.s. of Eq. (1b) have an analogous meaning compared to Eq. (1a), while $R\left(G_{\mathrm{w}}\right)$ represents the size dependent sources/sinks of the water mass concentration due to the microphysical processes coagulation/breakup. In an analogy to Eq. (2a), the budget equation (1b) can be formulated as

$$
\begin{aligned}
\frac{\partial G_{\mathrm{w}}}{\partial t} & =L_{\mathrm{mp}, 1}(\vec{x}, t)+L_{\mathrm{mp}, 2}(\vec{x}, t)+L_{\mathrm{mp}, 3}(\vec{x}, t)+L_{\mathrm{mp}, 4}(\vec{x}, t) \\
& =L_{\mathrm{mp}}(\vec{x}, t)
\end{aligned}
$$$$
t \in\left[t_{0}, T\right], \quad \vec{x} \in \mathfrak{R}^{4}, \quad G_{\mathrm{w}}\left(\vec{x}, t_{0}\right)=G_{\mathrm{w}, 0}(\vec{x}) .
$$

The basic principles for this approach, which is called 'operator splitting', were introduced by Marchuk (1975). The application of operator splitting to solve 3D chemistry-transport problems has been widely accepted for many years in the modelling of atmospheric chemical processes (e.g. Berkvens et al., 2000; McRae et al., 1982). A separate time integration of single processes such as advection, diffusion, and chemistry using efficient numerical solvers specifically designed for these subprocesses is the basis of operator splitting. Disadvantages, inherent to this method, are the creation of spatial concentration distribution which are relatively far away from the chemical equilibrium at the beginning of each 'chemical' time step (which also lead to an increase on the stiffness in the case of the chemical system) and splitting errors which add to the discretization errors and other errors due to the numerical solution method.
Currently, some attempts are being undertaken to investigate the effect of operator splitting for advectiondiffusion-gas phase chemistry problems (e.g. Müller et al., 1996; Verwer et al., 1998; Blom and Verwer, 1999; Berkvens et al., 2000). Theoretical derivations of the error due to operator splitting are, to date, available only for relatively simple (linear) systems (e.g. Murthy and Nanjundiah, 2000; Lanser and Verwer, 1998; Verwer and Sportisse, 1998; Strang, 1968).

Moreover, operator splitting is analogously applied to the complex micro-physical and multiphase chemical processes in clouds. In doing so, not only micro-physical processes are de-coupled from chemical processes, but also the micro-physical processes themselves (condensation/evaporation, coagulation, breakup, aerosol scavenging) are de-coupled as the gas phase reactions and the liquid phase reactions are treated separately in some cases (e.g. Hass, 1991).

In the calculation of the growth of droplets and aerosols due to the uptake of trace gases (the most important component being water vapour), the sensitive ratio of the corresponding supersaturation in the environment to the supersaturation at the particle's surface plays a central role. While the partial pressure in the particle environment is determined by dynamical processes in the case of water vapour, and by chemical gas phase reactions in the case of trace gases and the emission of corresponding precursors, the saturation vapour pressure at the particle's surface depends on the composition/concentration ratios of the particles of concern. The concentration ratios in the aerosols and droplets change by uptake of trace gases and aqueous phase chemical reactions. Furthermore, it is predominantly the phase change of water that affects the temperature in the near surroundings of the particles which has, in turn, an impact on the saturation water vapour pressure and on the saturation vapour pressure of all other trace gases. The phase change of water also establishes the link between cloud dynamics and microphysical and chemical processes, respectively.

The initial growth by the uptake of trace gases, consisting of mainly water vapour, determines both the efficiency and the onset of droplet interactions via coagulation and break-up and the collection efficiency of aerosol-droplet interaction. These redistribution processes over the particle size spectrum are very efficient for the redistribution of chemical substances and water (e.g. Flossmann et al., 1985; Müller and Mauersberger, 1994).

The exchange of water vapour as well as the redistribution mechanisms of particle constituents over the whole particle size range are size dependent and strongly non-linear. The de-coupling or linearization of the corresponding processes is expected to cause strong deviations from the solution of the completely coupled system for both the micro-physical and the chemical 
particle properties. This would have further consequences for the lifetime of clouds, their optical properties, the deposition behaviour of pollutants, etc.

The aim of this study is a systematic investigation of the errors in the simulated cloud micro-physical and chemical parameters generated by the de-coupled modelling of the corresponding processes in cloud models and cloud modules of air quality models as a function of the de-coupling period. Special emphasis is given to the size of aerosols and cloud droplets, liquid water content, liquid phase concentrations and their size distribution as well as the resulting partitioning of trace gases between the corresponding phases.

The following Sections 2 and 3 describe the applied model and the model set-up. Section 4 presents the results of the comparison between the base case simulations and those performed under operator splitting constraints. Recommendations and a summary are given in Sections 5 and 6.

\section{Model description}

In order to investigate the effect of operator splitting between micro-physical and multiphase chemical processes a simple box model is employed. To determine a clear cause-effect relationship, a relatively simple system of processes for a size distributed particle population is considered. Micro-physical processes are represented by condensation/evaporation, while multiphase chemistry complies the exchange of volatile trace gases between particles and the gas phase, as well as aqueous phase reactions. Hence, the initial problem (Eq. (1a) and (1b) and Eq. (2a) and (2b)) reduces to

$$
\begin{aligned}
& \frac{\partial c}{\partial t}=-\frac{\partial}{\partial r_{\mathrm{s}}}\left(\dot{r}_{\mathrm{s}} c\right)+R\left(r_{\mathrm{s}}, c\right)=L_{\mathrm{ch}, 2}\left(r_{\mathrm{s}}, c\right)+L_{\mathrm{ch}, 4}\left(r_{\mathrm{s}}, c\right), \\
& c=c\left(r_{\mathrm{s}}, t\right), \quad r_{\mathrm{s}} \in \mathfrak{R}^{1}
\end{aligned}
$$

$$
\begin{aligned}
& \frac{\partial G_{\mathrm{w}}}{\partial t}=-\frac{\partial}{\partial r_{\mathrm{s}}}\left(\dot{r}_{\mathrm{s}}, G_{\mathrm{W}}\right)=L_{\mathrm{mp}, 2}\left(r_{\mathrm{s}}, c\right), \\
& G_{\mathrm{W}}=G_{\mathrm{W}}\left(r_{\mathrm{s}}, t\right), \quad r_{\mathrm{s}} \in \mathfrak{R}^{1} .
\end{aligned}
$$

For practical use of Eq. (3), the operators $L_{\mathrm{ch}, 4}$ and $\dot{r}_{\mathrm{s}}$ have to be specified. A traditional way to describe the corresponding changes of a volatile compound $j$ in all phases is the separation of the general concentration vector $c$ into gas and aqueous phase species, respectively, denoted by $p_{j}$ and $c_{j}$. The exchange of volatile species between the aqueous and the gas phase is an important mechanism which determines subsequent reactions in the liquid phase. Therefore, compared to the Henryequilibrium approach, the numerically more expensive flux formulation according to Schwartz (1986) is employed. Within this framework, mass transport limitations are induced by the transport in the gas phase

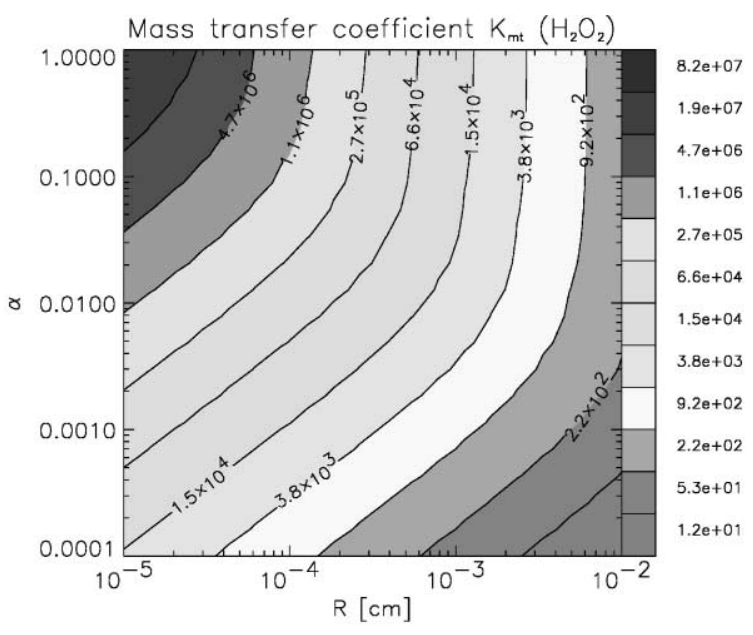

Fig. 1. Mass transfer coefficient of $\mathrm{H}_{2} \mathrm{O}_{2}$ as a function of various sticking coefficients $\alpha$ and particle sizes $r_{\mathrm{s}}$.

and by the interfacial transport. The dissociation equilibrium is assumed to be adjusted instantaneously as well as homogeneous concentration distributions within the drops. Hence, the mass transfer coefficient $k_{\mathrm{mt}, j}\left(\mathrm{~s}^{-1}\right)$ of the $j$ th chemical species is given by

$k_{\mathrm{mt}, j}^{-1}=\frac{r_{\mathrm{s}}^{2}}{3 D_{\mathrm{g}, j}}+\frac{4 r_{\mathrm{s}}}{3 \bar{v}_{j} \alpha_{j}}$,

where $D_{\mathrm{g}, j}$ and $\bar{v}_{j}$ represent the diffusivity and the mean velocity of molecules of the $j$ th trace gas in air, respectively, $\alpha_{j}$ is the gas specific sticking coefficient. Fig. 1 shows the principle behaviour of $k_{\mathrm{mt}, j}$ as a function of particle size and sticking coefficient. It becomes obvious from Fig. 1 that maximum uptake rates are reached for smallest particle sizes and biggest $\alpha$ values. The radial mass flux, $F_{j}\left(\mathrm{moll}^{-1} \mathrm{~s}^{-1}\right)$, between the gas phase and a single droplet with radius $r_{\mathrm{s}}$, and the flux between the gas phase and the whole droplet population, $\bar{F}_{j}(t)\left(\mathrm{moll}^{-1} \mathrm{~s}^{-1}\right)$, can be written as

$F_{j}\left(r_{\mathrm{s}}, t\right)=\frac{k_{\mathrm{mt}, j}}{\mathfrak{R}_{\mathrm{u}} T_{\infty}}\left(p_{j}(t)-\frac{c_{j}\left(r_{\mathrm{s}}, t\right)}{H_{j}^{*}\left(r_{\mathrm{s}}, t\right)}\right)$.

In Eq. (5), the flux $F_{j}$ is proportional to the concentration gradient between both phases, whereas $H_{j}^{*}$ represents the effective Henry coefficient, $\mathfrak{R}_{\mathrm{u}}$ is the universal gas constant and $T_{\infty}$ is the environmental temperature.

$\bar{F}_{j}(t)=\int_{0}^{\infty} F_{j}\left(r_{\mathrm{s}}, t\right) \frac{\mathrm{d} N\left(r_{\mathrm{s}}, t\right)}{\mathrm{d} r_{\mathrm{s}}} V\left(r_{\mathrm{s}}, t\right) \mathrm{d} r_{\mathrm{s}}$,

$V$ and $\mathrm{d} N / \mathrm{d} r_{\mathrm{s}}$ are the volume of drops with mass $m_{\mathrm{s}}\left(r_{\mathrm{s}}\right)$ and the drop number density in the size range $r_{\mathrm{s}}+\mathrm{d} r_{\mathrm{s}}$, respectively. With Eqs. (4)-(6) the local change of the partial pressures $p_{j}$, of the aqueous phase concentration 
Table 1

Diffusion coefficients, $D_{\mathrm{g}, j}$, and sticking coefficients, $\alpha_{j}$ for the uptake of gaseous species (1) Kirchner et al. (1990). (2) Mirabel et al. (1996). (3) Worsnop et al. (1989). (4) Schurath et al. (1996). (5) Ponche et al. (1993)

\begin{tabular}{lllc}
\hline $\mathrm{Gas}$ & $D_{\mathrm{g}, j}\left(\mathrm{~cm}^{2} \mathrm{~s}^{-1}\right)$ & $\alpha_{j}$ & Reference $\left(\alpha_{j}\right)$ \\
\hline $\mathrm{O}_{3}$ & 0.15 & 0.0042 & 1 \\
$\mathrm{HNO}_{3}$ & 0.13 & 0.11 & 2,5 \\
$\mathrm{H}_{2} \mathrm{O}_{2}$ & 0.18 & 0.13 & 2 \\
$\mathrm{HCl}$ & 0.18 & 0.08 & 3 \\
$\mathrm{CO}_{2}$ & 0.16 & 0.0002 & 4 \\
$\mathrm{SO}_{2}$ & 0.13 & 0.13 & 5 \\
$\mathrm{NH}_{3}$ & 0.25 & 0.097 & 2,5 \\
\hline
\end{tabular}

$c_{j}$, with $L_{\mathrm{ch}, 4}\left(r_{\mathrm{s}}, t\right)$ are determined by

$\frac{\partial p_{j}(t)}{\partial t}=-\mathfrak{R}_{\mathrm{u}} T_{\infty} \bar{F}_{j}(t)+T_{j}(t)$,

$\frac{\partial c_{j}}{\partial t}\left(r_{\mathrm{s}}, t\right)=F_{j}\left(r_{\mathrm{s}}, t\right)+U_{j}\left(r_{\mathrm{s}}, t\right)$,

$T_{j}$ and $U_{j}$ symbolize the sum of the source and sink chemical reactions of the $j$ th chemical species in the gas and in the aqueous phase, respectively. They depend on the choice of a specific reaction mechanism. Table 1 summarizes the considered gas phase species, their diffusion coefficients, $D_{\mathrm{g}, j}$, and sticking coefficients $\alpha_{j}$.

The used chemical reaction mechanism follows essentially the work of Walcek and Taylor (1986) and Lin and Chameides (1991). Besides the mass transfer of the trace gases between the gas and the aqueous phase, it comprises the most essential oxidation pathways of $\mathrm{S}(\mathrm{IV})$ to $\mathrm{S}(\mathrm{VI})$ by $\mathrm{O}_{3}$ and $\mathrm{H}_{2} \mathrm{O}_{2}$ in the liquid phase (Lagrange et al., 1991). The involved gas phase species have primary importance for the acidity development in the liquid phase (i.e. Pandis and Seinfeld, 1989). The applied formulation of the sulphur oxidation reactions follows Möller and Mauersberger (1995). Therefore, the employed reaction mechanism is representative for acid rain formation, and its complexity is, in spite of its relatively small number of reactions, sufficient to demonstrate the typical behaviour of stiff reaction mechanisms.

For the calculation of $L_{\mathrm{ch}, 2}$ and $L_{\mathrm{mp}, 2}$ the size and concentration dependent droplet growth rate $\dot{r}_{\mathrm{s}}$ must be specified. The size dependent formulation of the change of water mass $m_{\mathrm{w}}$ by condensation/evaporation of water (Eq. (9)) accounts for the temperature effect due to the release/uptake of latent heat by the phase change of water (first term in the exponential expression), the Kelvin effect (second term), and the Raoult effect (third term). In this study, we follow the description of Pruppacher and Klett (1997), and Jacobson (1997). The system of implicit equations for $\mathrm{d} m_{\mathrm{w}} / \mathrm{d} t$ is completed by an equation for the temperature at the particle surface, $T_{\mathrm{a}}$

$$
\begin{aligned}
\frac{\mathrm{d} r_{\mathrm{s}}(t)}{\mathrm{d} t}= & \frac{r_{\mathrm{s}}}{3 m_{\mathrm{w}}\left(r_{\mathrm{s}}, t\right)} \frac{\mathrm{d} m_{\mathrm{w}}\left(r_{\mathrm{s}}, t\right)}{\mathrm{d} t}=\frac{D_{\mathrm{v}}^{*} M_{\mathrm{w}} e_{\mathrm{sat}, \mathrm{w}}\left(T_{\infty}\right)}{r_{\mathrm{s}} \rho_{\mathrm{s}} \Re_{\mathrm{u}} T_{\infty}} \\
& \times\left(S_{\mathrm{v}}-\frac{1}{1+\delta} \exp \left[\frac{L_{\mathrm{e}} M_{\mathrm{w}}}{\mathfrak{R}_{\mathrm{u}} T_{\infty}} \frac{\delta}{1+\delta}\right.\right. \\
& \left.\left.+\frac{2 M_{\mathrm{s}} \sigma_{\mathrm{s}}\left(T_{\mathrm{a}}\right)}{\mathfrak{R}_{\mathrm{u}} T_{\mathrm{a}} \rho_{\mathrm{s}} r_{\mathrm{s}}} \frac{1}{1+\delta}-\frac{M_{\mathrm{w}}}{10^{3} \rho_{\mathrm{s}}} \sum c_{j}\left(r_{\mathrm{s}}, t\right)\right]\right) \\
\frac{T_{\mathrm{a}}\left(r_{\mathrm{s}}, t\right)}{T_{\infty}} & -1=\delta=\frac{1}{4 \pi} \frac{L_{\mathrm{e}} \rho_{\mathrm{s}}}{r_{\mathrm{s}} k_{\mathrm{a}}^{*} T_{\infty}} \frac{\mathrm{d} m_{\mathrm{w}}}{\mathrm{d} t} .
\end{aligned}
$$

In Eq. (9), $S_{\mathrm{v}}$ is the saturation ratio, $\rho_{\mathrm{s}}$ is the density of the solution, $M_{\mathrm{w}}$ and $M_{\mathrm{s}}$ are the molecular weight of water and the average molecular weight of the solute, and $e_{\mathrm{sat}, \mathrm{w}}$ and $L_{\mathrm{e}}$ are the water vapour saturation pressure and the heat of vaporization, $c_{j}\left(r_{\mathrm{s}}\right)$ is the molarity $\left(\mathrm{moll}^{-1}\right)$ of the aqueous phase species in particles of size $r_{\mathrm{s}}$. Activity effects are disregarded throughout this study assuming that all particles are highly diluted. This disregard, however, might be inaccurate for the smallest particles during the first few seconds of their growth (Müller, 1994). According to Eqs. (3) and (9) dilution/enrichment of $c_{j}$ by condensation/evaporation of water vapour is proportional to $\dot{m}_{\mathrm{w}} / m_{\mathrm{w}}$.

In the case of mutual interaction of micro-physical and multiphase chemical processes, Eqs. (3a) and (3b) are simultaneously solved with a Gear-solver (Hindmarsh, 1980). For the case of de-coupled treatment of the considered processes, Eq. (3a) is split up into two equations

$\frac{\partial c}{\partial t}=R\left(r_{\mathrm{s}}, c\right)=L_{\mathrm{ch}, 4}\left(r_{\mathrm{s}}, c\right)$,

$\frac{\partial c}{\partial t}=-\frac{\partial}{\partial r_{\mathrm{s}}}\left(\dot{r}_{\mathrm{s}}, c\right)=L_{\mathrm{ch}, 2}\left(r_{\mathrm{s}}, c\right)$.

Eqs. (10a), (3b) and (10b) are sequentially solved, whereby the latter equations are again simultaneously solved. This implies that the particle growth due to condensation is, on the one hand, ultimately linked to dilution of the aqueous phase chemical compounds. On the other hand, dilution leads to a reduced Raoult effect and reduces water vapour uptake. To solve these two systems of coupled equations, the Gear-solver is applied, too. The used tolerances for the error control of the Gear-solver are rtol=1e-4 and atol=1e-20. The Jacobian was numerically determined in all cases $(\mathrm{mf}=22)$.

Hence, beside at $t=0$ and around printout, Strang splitting is used on the differential equation level which retains second order accuracy (Strang, 1968; Gerisch and Verwer, 2000). Since the Gear-solver is used to solve all operators the influence of the numerical algorithm on the solution is the same in all the considered cases. 
Therefore, the resulting differences can be directly traced back to the de-coupling of processes.

\section{Set-up of the numerical experiments}

It is assumed that the arbitrarily selected de-coupling intervals (i.e. the integration periods for each operator) of $0.01,0.1,1,10,100,200,500$ and $1000 \mathrm{~s}$ are representative for the present day air quality models where dynamical and micro-physical/chemical processes are de-coupled as well. The integration time steps themselves are automatically chosen by the solver. The box is regarded as 'open' with respect to the thermodynamic parameters temperature $T_{\infty}$, relative humidity $\mathrm{RH}$, and pressure $P$. Very often these parameters are kept constant when applying the concept of operator splitting. With respect to the trace gases the box is considered to be 'closed' since trace gas concentrations are objects of the chemical processes. The initial

\section{Table 2}

Initial conditions for the box model simulations

\begin{tabular}{lcll}
\hline $\begin{array}{l}\text { Trace gas } \\
\text { species }\end{array}$ & $\begin{array}{l}\text { Mixing ratio } \\
(\mathrm{ppb}(V))\end{array}$ & $\begin{array}{l}\text { Thermodynamic } \\
\text { parameter }\end{array}$ & $\begin{array}{l}\text { Initial } \\
\text { value }\end{array}$ \\
\hline $\mathrm{H}_{2} \mathrm{O}_{2}$ & 1 & $T(\mathrm{~K})$ & 280 \\
$\mathrm{HNO}_{3}$ & 1 & $\mathrm{RH}(\%)$ & 100.1 \\
$\mathrm{NH}_{3}$ & 1 & $P(\mathrm{hPa})$ & 800 \\
$\mathrm{SO}_{2}$ & 5 & & \\
$\mathrm{HCl}$ & 0.5 & & \\
$\mathrm{CO}_{2}$ & 330 & & \\
$\mathrm{O}_{3}$ & 50 & & \\
\hline
\end{tabular}

conditions for both the considered trace gases and the thermodynamic parameters, given in Table 2, are chosen to represent average conditions in clouds.

The physico-chemical aerosol parameters are arbitrarily chosen for this study. The applied maritime aerosol distribution is constructed as a superposition of three log-normal distributions according to Jaenicke (1987) that is displayed in Fig. 2 (left panel). The selected size dependent distribution of the aerosol composition is shown in Fig. 2 (right panel). $\mathrm{NaCl},\left(\mathrm{NH}_{4}\right)_{2} \mathrm{SO}_{4}, \mathrm{SiO}_{2}$ are considered as initial aerosol components. For this study, the particle size range is arbitrarily selected according to the critical particle radius for activation, $r_{\mathrm{c}}$, at the given relative humidity RH. In Fig. 2, the bold parts of the lines indicate this size range with minimum dry and wet particle radii of $r_{\mathrm{c}}=5.4 \times 10^{-5} \mathrm{~cm}$ and $7.4 \times 10^{-5} \mathrm{~cm}$, respectively.

\section{Results}

This section presents the results for both the base case simulations, where all processes are treated simultaneously, for selected parameters and for splitting errors as a function of the de-coupling period. The differences in percent are calculated with respect to the base case simulation.

\subsection{Micro-physical parameters}

Starting with the micro-physical parameters of the particle population, Fig. 3 shows the spectral evolution

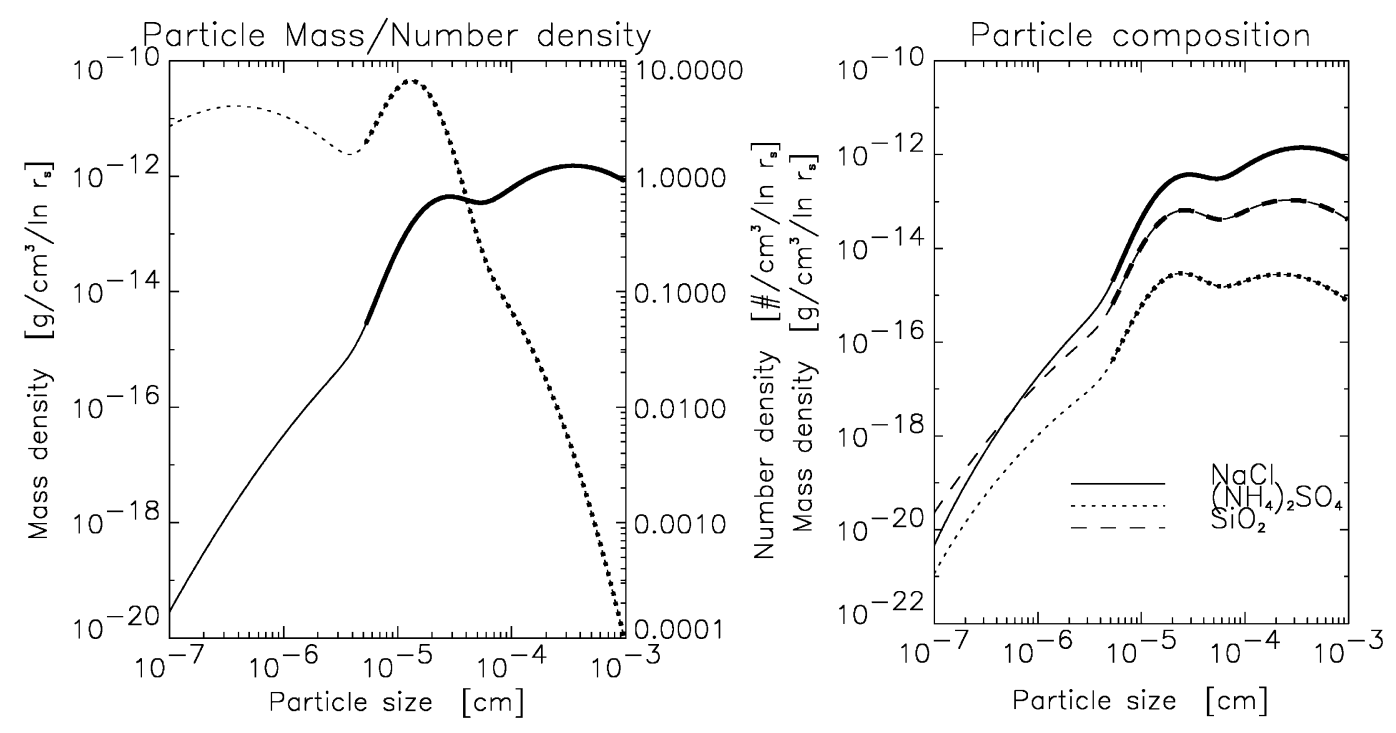

Fig. 2. Initial physico-chemical aerosol parameters. Left: particle mass density (solid line, left axis) and particle number density (dotted line, right axis); Right: particle composition is an internal mixture of the main components $\mathrm{NaCl}_{2}\left(\mathrm{NH}_{4}\right)_{2} \mathrm{SO}_{4}$, and $\mathrm{SiO}_{2}$. 

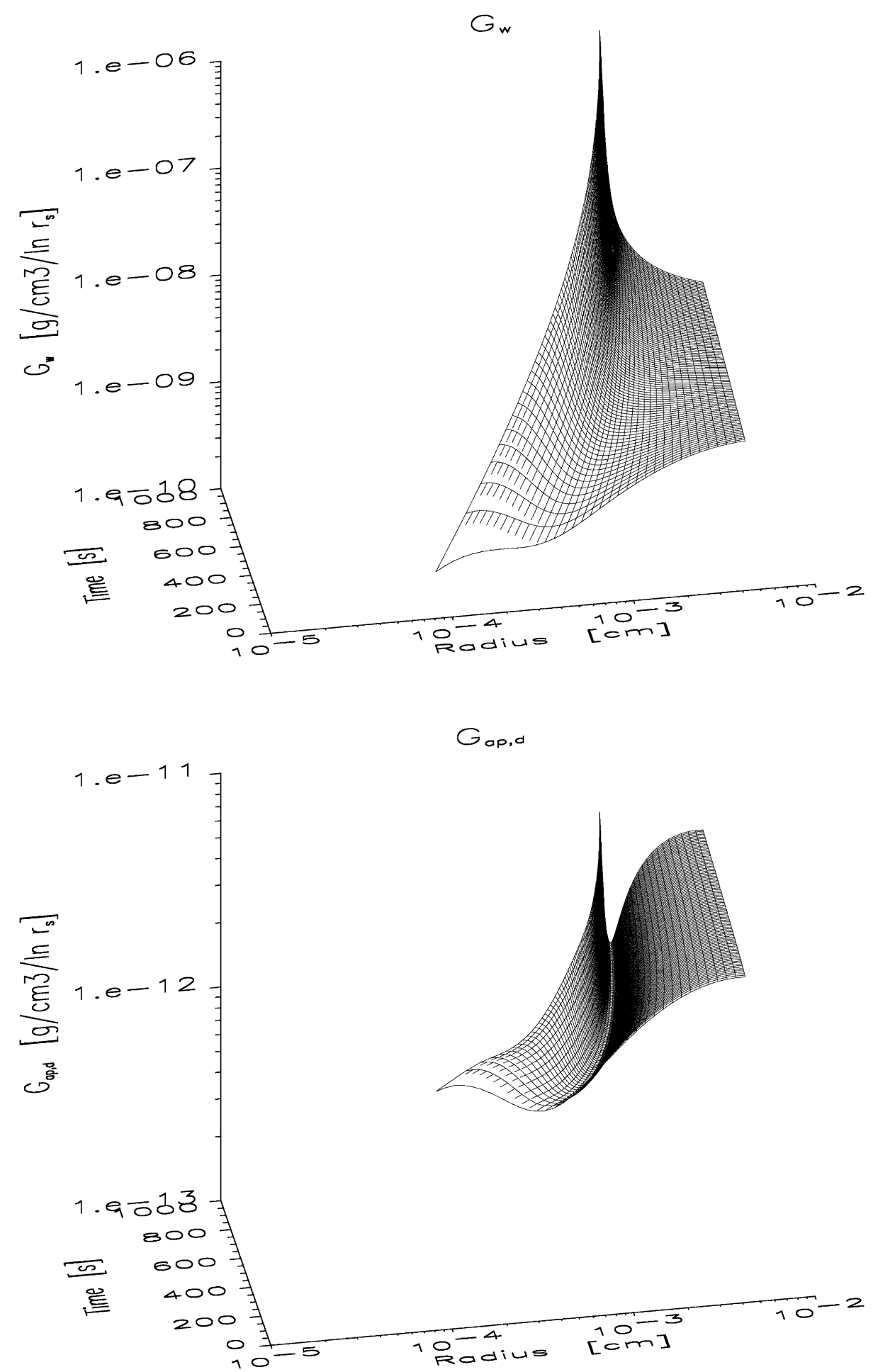

Fig. 3. Time development of the size dependent liquid water content $G_{\mathrm{w}}$ (top) and total content of chemical substances in the particles $G_{\text {ap, d }}$ (bottom) in units of $\mathrm{g}\left(\mathrm{cm}^{3} \text { air }\right)^{-1}$. 
of the size dependent liquid water content, $G_{\mathrm{w}}$, (top) and of the total mass of dissolved material, $G_{\mathrm{ap}, \mathrm{d}}$, in the particles (bottom) when all processes are considered simultaneously. Initial values are shown. With the increasing simulation time both the water content attached to the particles and the content of soluble aerosol mass increase considerably in the smallest size ranges due to the higher mass transfer coefficients relative to the bigger particle sizes. In addition, sulfur oxidation by ozone and $\mathrm{H}_{2} \mathrm{O}_{2}$ increases the total mass of dissolved matter. The minimum in the total aerosol content results primarily from two counteracting processes, namely size-dependent dilution by water vapour uptake and redistribution of volatile compounds over the particle spectrum via the gas phase.

Differences caused by varying de-coupling intervals are presented in Fig. 4. The differences in size integrated total liquid water content (top panel, output was done after the micro-physical operator step) become noticeable for de-coupling intervals above $1 \mathrm{~s}$. This can be explained by the characteristic times of water vapour diffusion which is about one order of magnitude smaller than $1 \mathrm{~s}$. A reduction of the de-coupling interval below $1 \mathrm{~s}$ does not significantly change the total liquid water content, but the size dependent water content of the particles is mainly influenced. With increasing decoupling intervals between micro-physical and multiphase chemical processes the total water content is increasingly underestimated in the case of de-coupled treatment. The difference reaches about $5-8 \%$ for $1000 \mathrm{~s}$ simulation time and de-coupling periods above about $200 \mathrm{~s}$. The differences in total liquid water content reach a maximum around 100-200 s simulation time for each de-coupling interval. This behaviour can be explained as follows. At the beginning of the growth simulation, the counteracting Kelvin and Raoult (or solution) effects are of special importance for the smallest particles which are characterized by the highest rates of water vapour as well as trace gas uptake, respectively. In the case of simultaneous interaction of dilution by condensation of water vapour and multiphase chemical processes, condensation causes enhanced fluxes of trace gases due to the reduction of the trace gas specific saturation vapour pressure at the particle surface. This, in turn, regenerates the depression/reduction of the water vapour saturation ratio at the particle surface (Raoult's law). In the case of de-coupled treatment, the water vapour fluxes towards the particle surfaces decrease faster for longer decoupling intervals due to rapid dilution since the mass of chemical substances in the individual particles is fixed during the micro-physical operator step. In these cases, the Raoult effect rapidly loses impact on the drop specific condensation rate. This mechanism is of decreasing importance for bigger particles, and hence of decreasing importance for increasing simulation time.
The time evolution of the differences between simultaneous and de-coupled treatment of the processes, with respect to total mass dissolved in the particles (Fig. 4, bottom), is qualitatively different from that of the total liquid water content. In general, one can observe an overestimation of the total amount of admixtures in the cloud elements (droplets, aerosols) for the case with operator splitting compared to the completely coupled case. The overestimation increases with increasing de-coupling periods due to increasing dilution during the preceding micro-physical operator step. Higher dilution of the particles (compared to the coupled case) causes higher uptake rates of volatile chemical species and enhanced irreversible aqueous phase reactions of the corresponding precursor species. The decreasing overestimation with increasing simulation time is caused by the limitation of the gas phase precursor concentrations in the course of the simulation time. The splitting error for the total mass of chemical matter inside the particles reaches a maximum of 15$20 \%$ for de-coupling intervals of $100-1000 \mathrm{~s}$ at the beginning of the simulation. This error gradually decreases to about $5 \%$ after 1000 s simulation time.

Differences in the total water content and total mass of chemical compounds result in differences in particle size. Fig. 5 shows the corresponding differences of the smallest particle size category with respect to the base case. The smallest particle grow from about $1.5 \mu \mathrm{m}$ at $10 \mathrm{~s}$ to about $12 \mu \mathrm{m}$ after $1000 \mathrm{~s}$ simulation. According to the Figs. 4-6, the time evolution of the differences in particle size (especially of the smallest particles) follows essentially the temporal development of the difference in total water content of the particles.

For de-coupling periods above $10 \mathrm{~s}$, the differences in particle radius reach a maximum of about $7 \%$ after $50 \mathrm{~s}$ of individual lifetime. This maximum decreases to $1 \%$ for all de-coupling intervals above $10 \mathrm{~s}$ at the end of the simulation time. Examining the radius differences for the whole particle size distribution (Fig. 6) reveals that considerable deviations persist only in the size range below about $20 \mu \mathrm{m}$. Fig. 6 illustrates the shrinking of the maximum deviation and the affected particle size range with decreasing de-coupling intervals. The smallest size fractions always show the highest underestimation of particle size in the case of de-coupling. This is of special importance for the determination of the optical properties, which are very sensitive to the small particle size range.

\subsection{Chemical composition of the particles}

The size dependent development of the species concentration in the particles is determined by both dilution due to water vapour uptake and chemical reactions in the aqueous phase including the exchange of volatile species between the surrounding gas phase and 

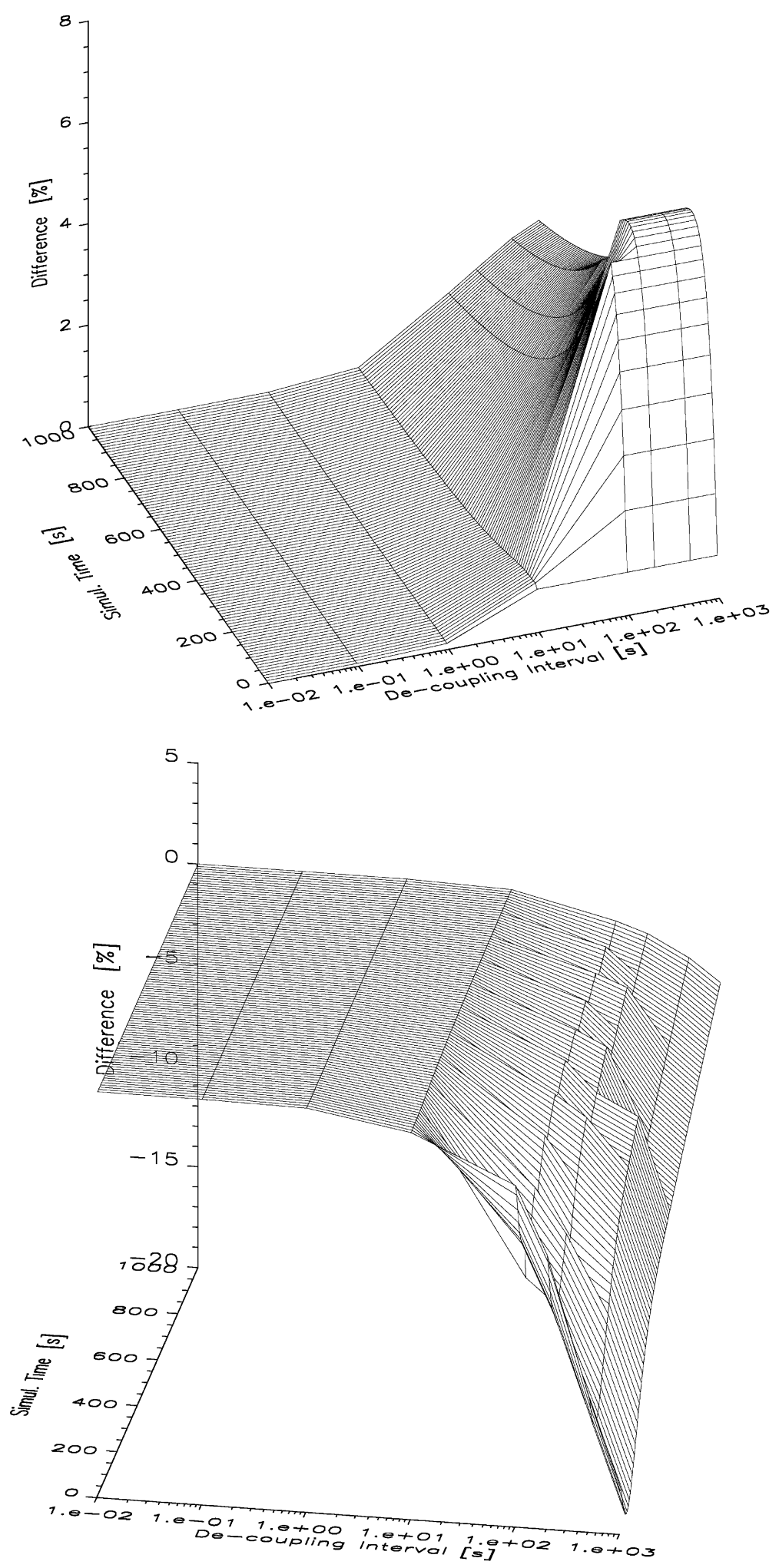

Fig. 4. Percent difference between completely coupled and de-coupled model runs as a function of de-coupling interval and of simulation time. Total liquid water content (top) and total dissolved mass in the particles (bottom). 


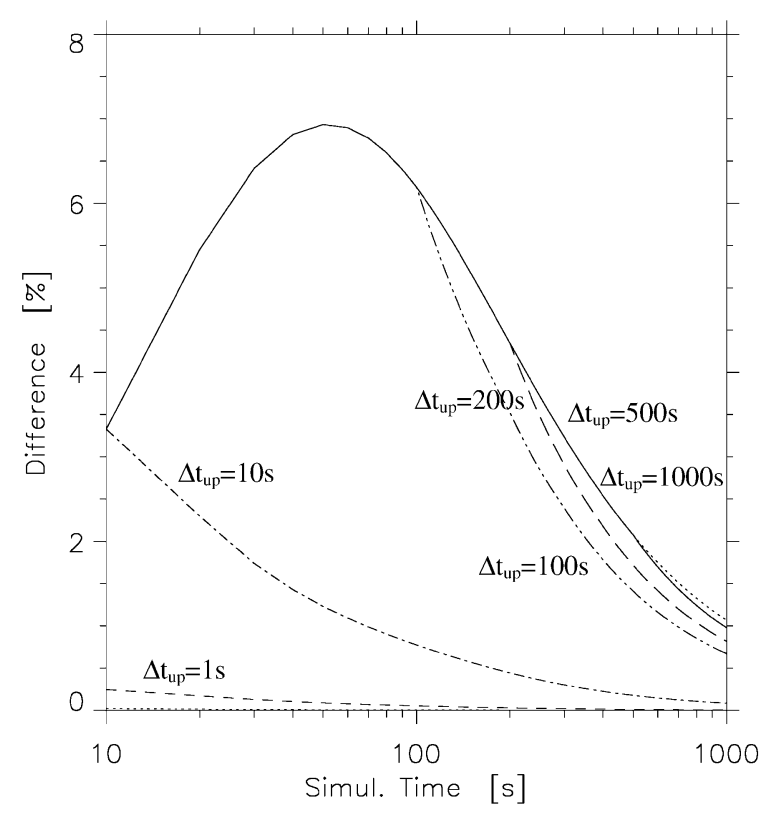

Fig. 5. Time evolution of the percent differences for the smallest particles $\left(r_{\mathrm{s}}(t=0)=7.4 \times 10^{-5} \mathrm{~cm}\right)$ for different decoupling periods.

the particles. Hence, the time rate of change of $c_{j}$ could be written as

$\frac{\partial c_{j}\left(r_{\mathrm{s}}\right)}{\partial t} \propto \frac{c_{j}\left(r_{\mathrm{s}}\right)}{m_{j}\left(r_{\mathrm{s}}\right)} \frac{\partial m_{j}\left(r_{\mathrm{s}}\right)}{\partial t}-\frac{c_{j}\left(r_{\mathrm{s}}\right)}{m_{\mathrm{w}}\left(r_{\mathrm{s}}\right)} \frac{\partial m_{\mathrm{w}}\left(r_{\mathrm{s}}\right)}{\partial t}$.

In Eq. (11), $m_{\mathrm{w}}$ and $m_{j}$ are the droplet water mass and the total mass of chemical compounds inside a single droplet. Since the admixtures in the particles partially consist of chemically rather inert species like $\mathrm{SiO}_{2}$, sodium, etc. the concentration change of those species is caused only by the change of the water content. Hence, the magnitude of the size dependent and size integrated splitting error, respectively, experienced by chemically inert species is inversely proportional to the splitting error of the liquid water content. As an example for chemically inert aerosol species, Fig. 7 shows the spectral evolution of sodium ions in solution for the base case (Fig. 7a) and for the case of a de-coupling interval of $\Delta t_{\text {up }}=1000 \mathrm{~s}$ (Fig. 7b). The results (also for the following pictures) are shown at the end of the full integration step. These pictures demonstrate the distinct effect of operator splitting on the evolution dynamics of chemically inert species. The molar concentration of $\mathrm{Na}^{+}$continuously changes with changes of the particle spectrum (Fig. 7a), while in the case of operator splitting (Fig. 7b) the particles have already reached their final size and $\mathrm{Na}^{+}$concentration before the chemical operator starts. As one could expect, the time evolution of the corresponding splitting error for the integral sodium concentration as a function of the de-coupling interval shown in Fig. $7 \mathrm{c}$ obeys the equation $\dot{c}_{j}\left(r_{\mathrm{s}}\right) / c_{j} \times$ $\left(r_{\mathrm{s}}\right) \propto-\dot{m}_{\mathrm{w}}\left(r_{\mathrm{s}}\right) / m_{\mathrm{w}}\left(r_{\mathrm{s}}\right)$.

Beside the micro-physical processes, even aqueous phase chemical reactions as well as interfacial exchange of volatile compounds contribute to the concentration change of chemically active species in the particles. Again, one can expect stronger effects due to operator splitting in the smaller size ranges caused by larger mass transfer coefficients, $k_{\mathrm{mt}, j}$, in this size range compared to bigger particles. For one of the main constituents, namely sulphate, dilution due to water vapour uptake dominates the sulphate production in the small particles due to the uptake of $\mathrm{SO}_{2}$ and subsequent oxidation processes by ozone and $\mathrm{H}_{2} \mathrm{O}_{2}$ in the case of simultaneous treatment of all relevant processes (Fig. 8a). For particles larger than $r_{\mathrm{s}} \sim 30 \mu \mathrm{m}$, dilution is less effective than SIV oxidation due to the strong size dependence of $\dot{r}_{\mathrm{s}}$. De-coupling micro-physical and chemical processes leads to a strong dilution of all aqueous phase species, not only of sulphate, during the micro-physical operator step over the whole particle size range. Fig. $8 \mathrm{~b}$ illustrates this. At time $t=0$ of the chemical operator step the final sulphate concentration distribution over the size range after the micro-physical operator step is shown in the case of a de-coupling interval $\Delta t_{\text {up }}=1000 \mathrm{~s}$. During the subsequent chemical operator step no further dilution by water vapour takes place. The resulting fluxes of volatile compounds caused by the preceding dilution and subsequent oxidation processes overcompensate the effect of reduced mass transfer coefficients related to larger particle sizes at the end of the micro-physical operator step compared to the coupled case. This results in a maximum total sulphate overestimation by about $60 \%$ in the case of $\Delta t_{\text {up }}=1000 \mathrm{~s} \mathrm{(Fig.} \mathrm{8c).} \mathrm{Since} \mathrm{the} \mathrm{gas}$ phase reservoir of precursor species is limited (closed box assumption), the splitting error reduces (to about $30 \%$ in the presented case) with increasing simulation time for a fixed de-coupling interval.

The corresponding time evolution of the splitting error for sulphate related compounds in the gas phase, $\mathrm{SO}_{2}$, and sulphur in the aqueous phase, $\mathrm{SIV}$, is shown in Fig. 9. Since de-coupling results in an overestimation of total particle sulphate, the $\mathrm{SO}_{2}$ gas phase concentration is underestimated in this case. Fig. $9 \mathrm{~b}$ impressively demonstrates the abrupt concentration changes of volatile compounds during the changes of operators. At the beginning of each chemical operator step, the differences are always negative since SIV was not reduced due to oxidation reactions in the de-coupled cases. In the course of the chemical operator step SIV is more efficiently removed compared to the coupled case. This results in the positive concentration differences towards the end of the chemical operator step.

Since the overprediction of sulphate results in lower $\mathrm{pH}$ values in the de-coupled cases another consequence of operator splitting is a higher degassing rate of very 

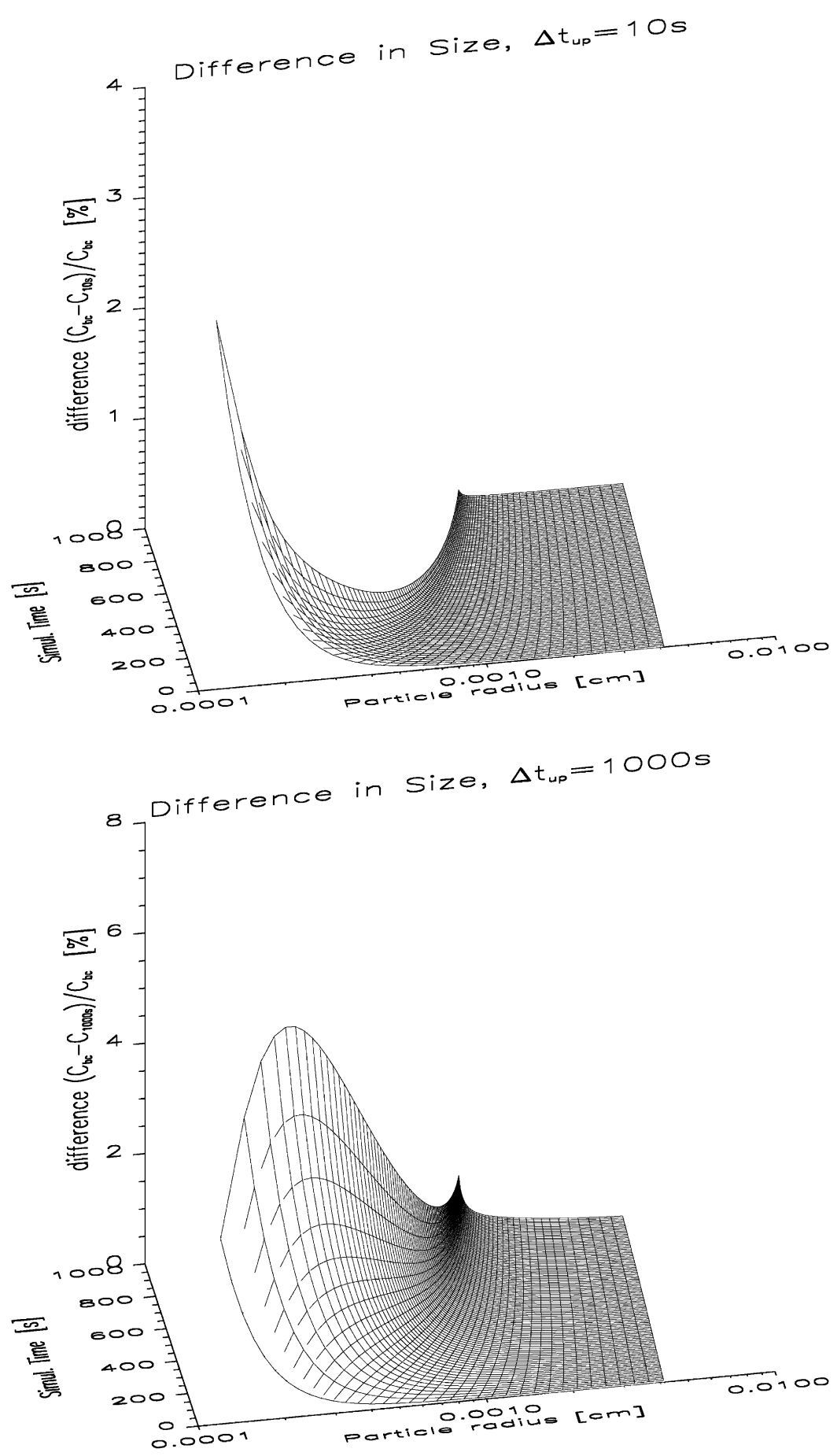

Fig. 6. Temporal and size dependent development of the percent difference of the radii for two different de-coupling periods: $10 \mathrm{~s}$ (top) and $1000 \mathrm{~s}$ (bottom).

volatile dissociating species like $\mathrm{HNO}_{3}$ or $\mathrm{HCl}$ for longer de-coupling intervals (not shown here).

To complete the investigation of the consequences of operator splitting, Fig. 10 shows the time evolution of gas phase concentrations of selected species, which are present in all considered phases, for the base case and all considered de-coupling intervals. The step function-like behaviour of the concentration change again indicates 

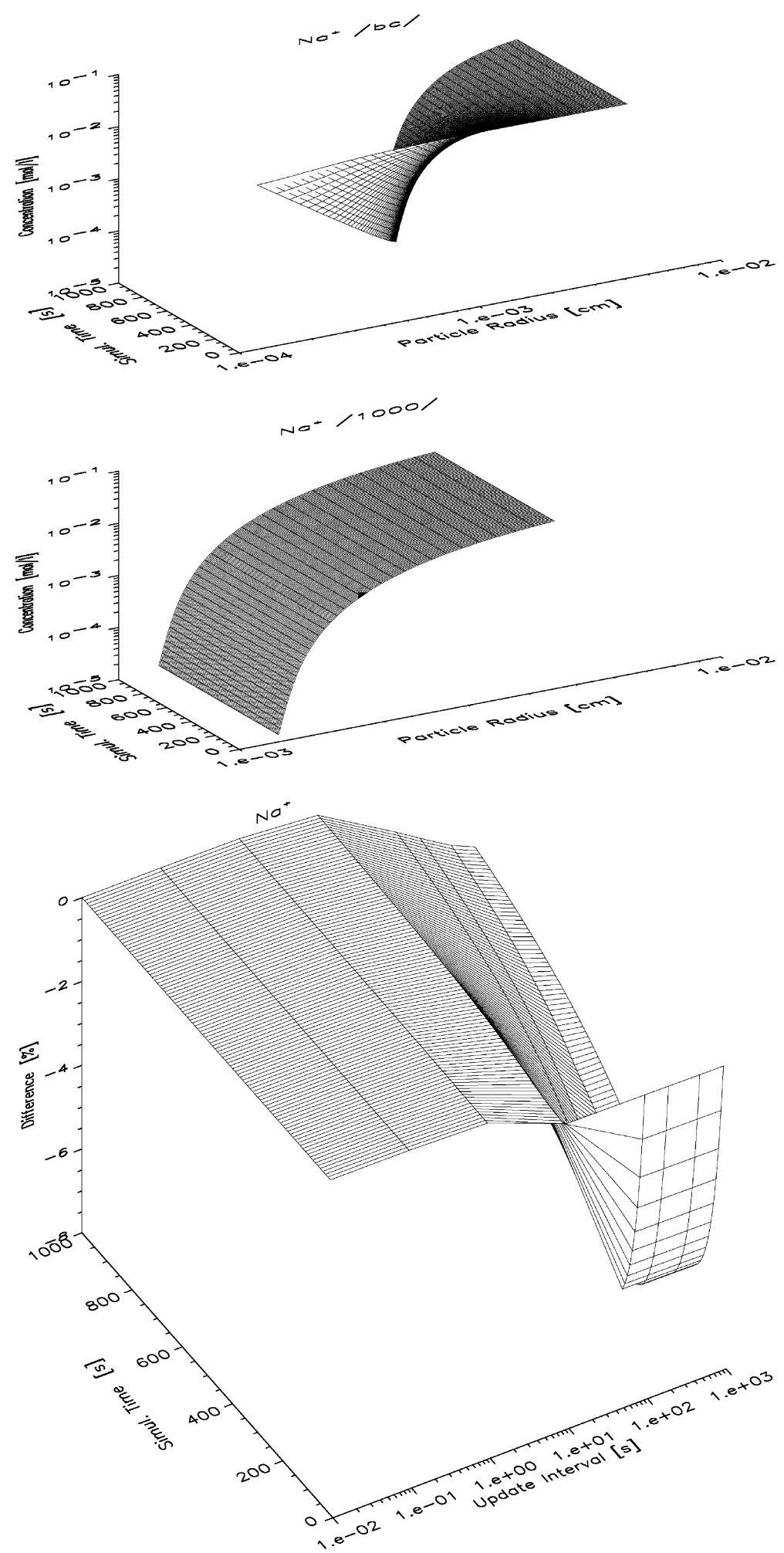

Fig. 7. Spectral evolution of $\mathrm{Na}^{+}$for (a) the base case, (b) the de-coupled case $\Delta t_{\text {up }}=1000 \mathrm{~s}$, and (c) for the percent differences of total aqueous phase sodium due to operator splitting. 

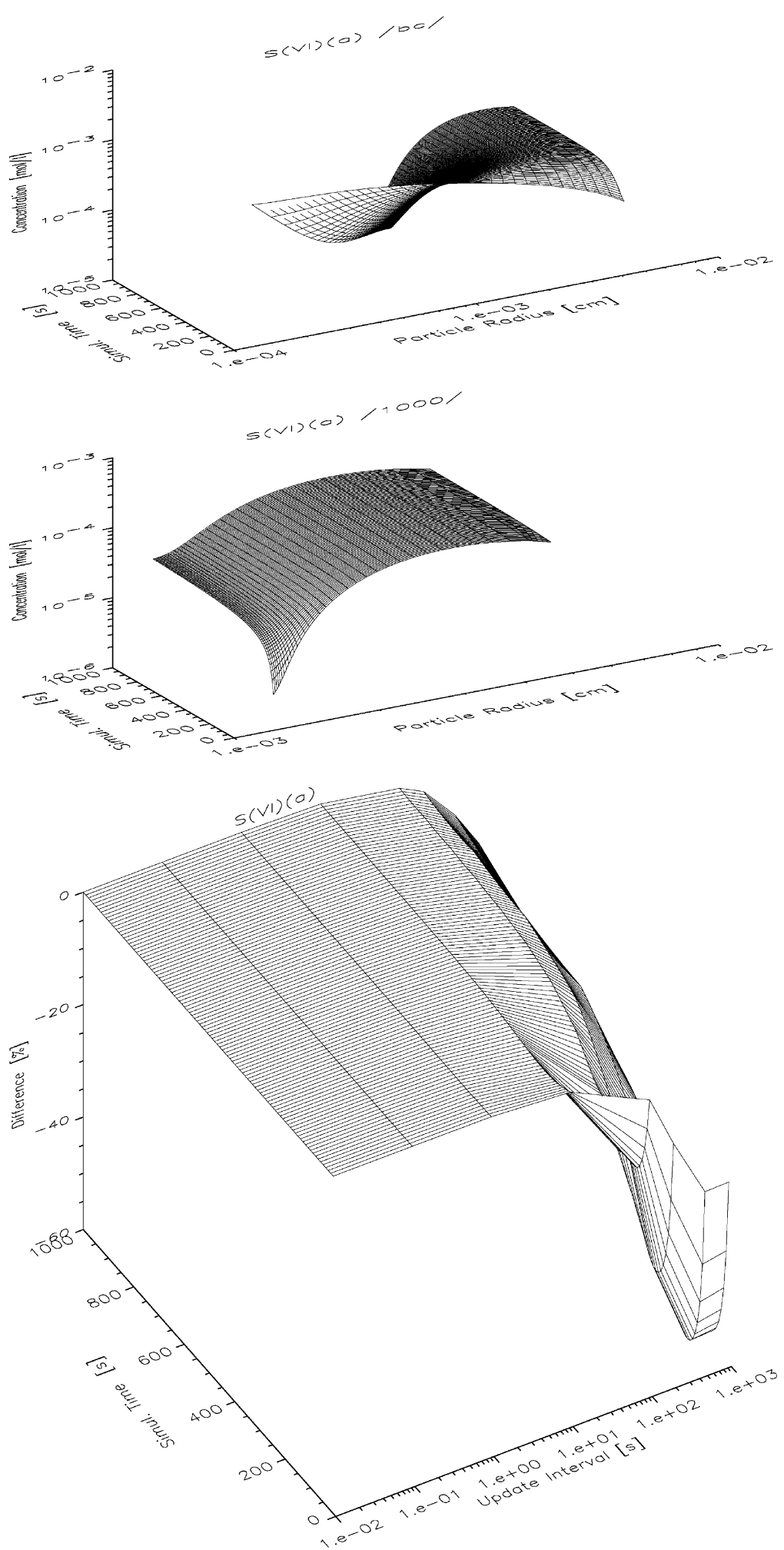

Fig. 8. Same as Fig. 7, but for aqueous phase sulphate. 

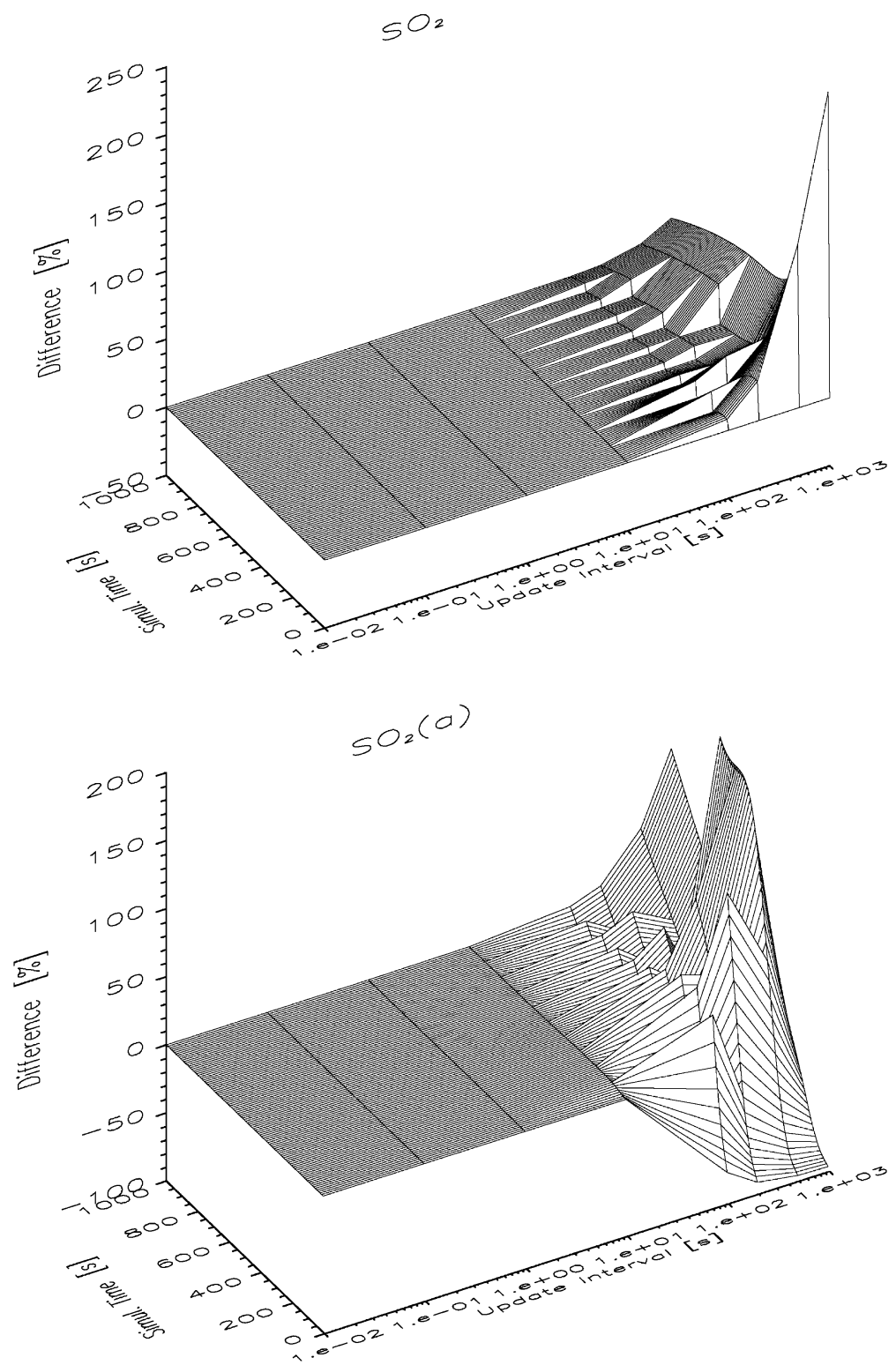

Fig. 9. Percent differences of sulphate related compounds as a function of simulation time and de-coupling interval: (a) gas phase $\mathrm{SO}_{2}$, (b) total aqueous phase SIV.

the operator change for all de-coupled cases. For most of the species, de-coupled treatment of the processes results in an underestimation of the gas phase concentrations compared to the simultaneous calculation of the corresponding equations. Concentration differences of the gas phase species shown in Fig. 10, locally generated by operator splitting, will affect further evolution of gas phase species especially in cloud-free grid boxes when transport processes will be additionally considered.

\section{Recommendations}

Having estimated the tendency and the magnitude of the splitting error as a function of the de-coupling interval one can derive upper limits for the length of the de-coupling interval to produce valid simulation results for given error thresholds with models where operator splitting is applied. For the tested system of microphysical and multiphase chemical processes the following conclusions can be drawn: 

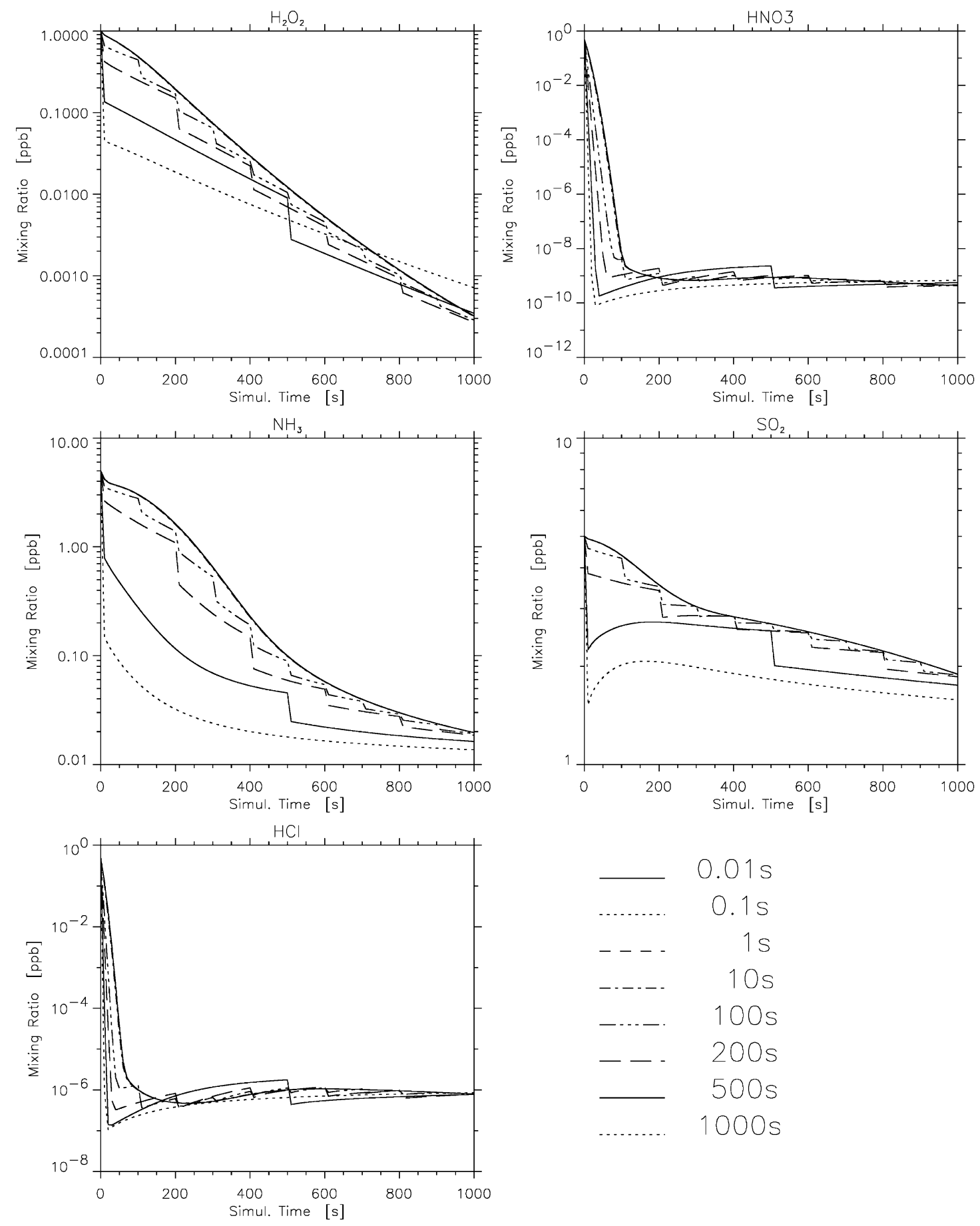

Fig. 10. Time dependence of selected gas phase concentrations for de-coupling intervals indicated in the legend (lines for de-coupling intervals less than or equal to $10 \mathrm{~s}$ overlie each other).

- The effect of operator splitting is especially important for all particles smaller than about $10 \mu \mathrm{m}$, i.e. for all aerosols and most cloud droplets.
- To limit splitting errors to less than $1 \%$ for integral quantities such as total liquid water content or total amount of chemical substances inside the 
particle, de-coupling intervals less than $10 \mathrm{~s}$ have to be used.

- For size-dependent quantities such as the evolving particle size itself, chemical composition, or water content attached to particles of a certain size, decoupling intervals shorter than $1 \mathrm{~s}$ are necessary to keep the splitting error below $1 \%$.

\section{Summary}

The objective of this preliminary study was a systematic investigation of the splitting error for mutually interacting cloud micro-physical and multiphase chemical processes under characteristic conditions using a box model.

It was shown that both micro-physical and chemical properties of the particles are affected by operator splitting. The splitting error shows a very strong size dependence, whereby the properties of the smallest particle sizes are more affected due to smaller time scales of the trace gas fluxes (including water vapour) between the phases for smaller particles and the non-commutativity of the split operators. In the case of de-coupled treatment of the processes, the liquid water content is underestimated by $5-10 \%$, while the total aerosol content is overestimated by about $20 \%$. More specifically, the concentrations of chemically inactive species (here $\mathrm{Na}^{+}, \mathrm{SiO}_{2}$, etc.) or highly soluble species like $\mathrm{HCl}$ are overestimated by the same amount as the liquid water content is underestimated in the case of decoupled treatment of the corresponding processes. Chemical product species in the aqueous phase like SVI are increasingly overestimated with increasing decoupling periods. This is mainly the result of the state of the aqueous phase at the end of the micro-physical operator step, which is equally the beginning of the chemical operator step. This state of operator change can be characterized as highly diluted with a higher $\mathrm{pH}$ compared to the coupled case. These conditions lead to higher fluxes of volatile compounds towards the particle surfaces, and in the case of sulphur oxidation to higher oxidation rates via $\mathrm{O}_{3}$ and $\mathrm{H}_{2} \mathrm{O}_{2}$ for the operator splitting case.

The effect of changed operator sequence was not explicitly investigated. However, based on the work of Verwer and Sportisse (1998) an optimal operator sequence was already chosen since the chemical processes tend to force the system towards its equilibrium state. It is, therefore, expected that a change of the operator sequence would lead to an increase of the concentration differences for the chemical compounds. The results for the micro-physical properties such as liquid water content would not experience bigger changes since water vapour is not limited in the used model set-up.
One could argue that the arbitrary choice of the physico-chemical aerosol properties and of the environmental conditions might influence the demonstrated results. However, we think that such an arbitrary selection could only slightly modify our results, but would neither have an effect on the order of magnitude of concentration variations due to operator splitting, nor on the overall conclusions drawn. Further investigations are necessary to estimate the splitting errors in more complex systems (additional micro-physical processes) and to identify those processes which could be efficiently treated separately with only little loss of accuracy. For those processes which cause considerable splitting errors alternative numerically efficient solution techniques have to be developed.

\section{References}

Berkvens, P.J.F., Botchev, M.A., Verwer, J.G., Krol, M.C., Peters, W., 2000. Solving vertical transport and chemistry in air pollution models. CWI-Report MAS-R0023.

Blom, J.G., Verwer, J.G., 1999. A comparison of integration methods for atmospheric transport-chemistry problems. CWI-Report, MAS-R9910.

Flossmann, A.I., Hall, W.D., Pruppacher, H.R., 1985. A theoretical study on the wet removal of atmospheric pollutants. Part I: The redistribution of aerosol particles captured through nucleation and impaction scavenging by growing cloud drops. Journal of Atmospheric Science 42, 583-606.

Gerisch, A., Verwer, J.G., 2000. Operator splitting and approximate factorization for taxis-diffusion-reaction models. CWI-Report MAS-0026.

Hass, H., 1991. Description of the EURAD (European Air Pollution Dispersion Model) chemistry transport model (CTM2), Mitteilungen aus dem Institut für Geophysik und Meteorologie der Univ. zu Köln, Heft 83.

Hindmarsh, A.C., 1980. LSODE and LSODI, Two new initial value ordinary differential equation solvers. ACM-SIGNUM Newsletter 15 (4), 10-11.

Jacobson, M.Z., 1997. Numerical techniques to solve condensational and dissolutional growth equations when growth is coupled to reversible aqueous reactions. Aerosol Science and Technology 27, 491-498.

Jaenicke, R., 1987. Aerosolphysics and chemistry. In: Fischer (Ed.), Physical and Chemical Properties of the Air, Vol. 46. Landold-Börnstein Neue Serie, Springer, Berlin.

Kirchner, W., Welter, F., Bongartz, A., Kames, J., Schweigehofer, S., Schurath, U., 1990. Trace gas exchange at the air/ water interphase: measurements of mass accomodation coefficients. Journal of atmospheric Chemistry 10, 427-449.

Lagrange, J., Paalares, C., Wenger, G., Lagrange, P.H., 1991. Mechanism of the aqueous oxidation of sulphur (IV) to sulphur (VI) by strong oxidants. In: Borrell (Ed.), EUROTRAC Annual Report 1991, Part 6, HALIPP, GarmischPartenkirchen, pp. 28-33. 
Lanser, D., Verwer, J.G., 1998. Analysis of operator splitting for advection-diffusion-reaction problems from air pollution modelling. CWI-Report, MAS R9805.

Lin, X., Chameides, W.L., 1991. Model studies of the impact of chemical inhomogeneity on $\mathrm{SO}_{2}$ oxidation. Journal of Atmospheric Chemistry 13, 109-129.

Marchuk, G.I., 1975. Methods of Numerical Mathematics. Springer, New York, 316 pp.

McRae, G.J., Goodin, W.R., Seinfeld, J.H., 1982. Numerical solution of the atmospheric diffusion equation for chemically reacting flows. Journal of Computational Physics 86, 187-210.

Mirabel, P.H., George, C.H., Magi, L., Ponche, J.L., 1996. In: Warneck, P. (Ed.), Gas-liquid Interactions, Heterogeneous and Liquid Phase Processes, Vol. 2. Springer, Berlin, pp. 175-181.

Möller, D., Mauersberger, G., 1995. Aqueous chemical reaction system used in cloud chemistry modelling. In: Flossmann, A., Cvitas, T. (Eds), Clouds: Models and Mechanisms, EUROTRAC ISS, Garmisch-Partenkirchen. EUROTRAC Special Publication.

Müller, F., 1994. Zur spektralen Modellierung der Wechselwirkung wolkenchemischer und mikrophysikalischer Prozesse. Fraunhofer-Institut für Atomsphärische Umweltforschung, Bd. 30-94, Garmisch-Partenkirchen, p. 209 (in German).

Müller, F., Mauersberger, G., 1994. Case study on the interaction of size dependent multiphase chemistry and detailled microphysics. Atmospheric Research 32, 273-288.

Müller, F., Clappier, A., Kübler, J., Reiss, H., Martilli, A., Russell, A. G., Krüger, B. C., van den Bergh, H., 1996. Further development of a comprehensive air quality model, to include aqueous phase and aerosol chemistry for calculating fluxes of ozone, as well as nitrogen and sulphur containing pollutants in Europe, Final Report of the EUREKA-EU7/EUROTRAC sub-Project BBW-EUREKA (93)2.
Murthy, A.S.V., Nanjundiah, R.S., 2000. Time splitting errors in the numerical integration of semilinear systems of ordinary differential equations. Monthly Weather Review 128, 3921-3926.

Pandis, S.N., Seinfled, J.H., 1989. Mathematical modelling of acid deposition due to radiation fog. Journal of Geophysical Research 94, 12911-12923.

Ponche, J.L., George, Ch., Mirabel, Ph., 1993. Mass transfer at the air/water interface: mass accommodation coefficients of $\mathrm{SO}_{2}, \mathrm{HNO}_{3}, \mathrm{NO}_{2}$ and $\mathrm{NH}_{3}$. Journal of Atmospheric Chemistry 16, 1-21.

Pruppacher, H.R., Klett, F., 1997. Microphysics of Clouds and Precipitation. Kluwer Academic Publishers, Dordrecht, 954 pp.

Schurath, U., Bongartz, A., Kames, J., Wunderlich, C., Carstens, T., 1996. In: Warneck, P. (Ed.), Gas-liquid Interactions, Heterogeneous and Liquid Phase Processes, Vol. 2. Springer, Berlin, pp. 182-189.

Schwartz, S.E., 1986. Mass-transport considerations pertinent to aqueous phase reactions of gases in liquid water clouds. In: Jaeschke, W. (Ed.), Chemistry of Multiphase Atmospheric Systems, NATO ASI Series, Series G: Ecological Science, Vol. 6. pp. 415-472.

Strang, G., 1968. On the construction and comparison of difference schemes. SIAM Journal of Numerical Analysis 5, 509-517.

Verwer, J.G., Sportisse, B., 1998. A note on operator splitting in a stiff linear case. CWI-Report, MAS-R9830.

Verwer, J.G., Hundsdorfer, W.H., Blom, J.G., 1998. Numerical time integration for air pollution models. CWI-Report, MAS-R8925.

Walcek, C.J., Taylor, G.R., 1986. A theoretical method for computing vertical distributions of acidity and sulphate production within cumulus clouds. Journal of atmospheric Science 43, 871-876.

Worsnop, D.R., Zahniser, M.S., Kolb, C.E., Gardner, J.A., Watson, L.R., van Doren, J.M., Jayne, J.T., Davidovits, P., 1989. Journal of Physical Chemistry 93, 1159-1172. 